\title{
Carotid Near-Occlusion: A Comprehensive Review, Part 1- Definition, Terminology, and Diagnosis
}

\author{
E. Johansson and A.J. Fox
}

\begin{abstract}
SUMMARY: Carotid near-occlusion is distal ICA luminal collapse beyond a tight stenosis, where the distal lumen should not be used for calculating percentage stenosis. Near-occlusion with full ICA collapse is well-known, with a threadlike lumen. However, near-occlusion without collapse is often subtle and can be overlooked as a usual severe stenosis. More than 10 different terms have been used to describe near-occlusion, sometimes causing confusion. This systematic review presents what is known about carotid near-occlusion. In this first part, the foci are definition, terminology, and diagnosis.
\end{abstract}

ABBREVIATION: ECA $=$ external carotid artery

C arotid near-occlusion is distal luminal collapse of the internal carotid artery beyond a tight stenosis. ${ }^{1}$ Various terms have been used to describe near-occlusion, which can mislead students or those doing literature searches: near-occlusion ${ }^{1-44}$ (or "near total occlusion" ${ }^{\text {45-51 }}$ ), pseudo-occlusion, ${ }^{1-20,43,45,47,48,50-70}$ string sign, ${ }^{1-5,7,9-13,16,18-20,22,24,26,30,40,42,43,45,47-50,52,56,60-62,65,66,68-74}$ slim sign, $1,2,4,6,9-20,28,31,45,47-51,55,59,60,62,64,68,69,71,72,75$ critical stenosis, ${ }^{50,70}$ small or narrow distal internal carotid artery (with variations), ${ }^{1,11,28,36,39-42}$ preocclusive stenosis, ${ }^{5,46,50,62,64,67}$ subtotal stenosis, ${ }^{67,76,77}$ subtotal occlusion, ${ }^{1,9,40,72}$ functional occlusion, ${ }^{40}$ subocclusion, ${ }^{50}$ hypoplasia, ${ }^{11,12,18,45} 99 \%$ stenosis, ${ }^{66}$ hairline residual lumen, ${ }^{20,43}$ and incomplete occlusion. ${ }^{1}$

Calculating percentage stenosis for carotid near-occlusion is fallacious, and near-occlusion assessment is advised before measuring for percentage stenosis. ${ }^{1,2,32,34}$ Near-occlusion with full collapse is well-recognized as a threadlike distal lumen. However, partial distal collapse is subtle-near-occlusion without full collapse is sometimes overlooked as stenosis. Carotid near-occlusion was described in 1970 as the carotid slim sign, a severe collapse, and today as near-occlusion with full

Received February 28, 2015; accepted after revision April 8.

From the Department of Pharmacology and Clinical Neuroscience (E.J.), Umeå University, Umeå, Sweden; and Department of Neuroradiology (A.J.F.), Sunnybrook Heath Sciences Centre, University of Toronto, Toronto, Ontario, Canada.

This study was funded by the Swedish Stroke Foundation, the Northern Swedish Stroke Fund, the Foundation for Neuroscientific research at Umeå University Hospital, the County of Västerbotten, and the medical faculty of Umeå University.

Please address correspondence to Elias Johansson, MD, Department of Neurology, Institution of Pharmacology and Clinical Neuroscience, Umeå University,

90182 Umeå, Sweden; e-mail: elias.johansson@umu.se

-- Indicates open access to non-subscribers at www.ajnr.org

http://dx.doi.org/10.3174/ajnr.A4432 collapse (Figs 1-5). ${ }^{75}$ The near-occlusion definition was widened to recognize partial collapse (near-occlusion without full collapse) (Figs 1-5)., ${ }^{1,2}$

The aim of this review was to present the definition, terminology, diagnosis, prognosis, treatment, and pathophysiology of carotid near-occlusion; highlight areas of confusion; and highlight areas in need of future improvement. In this first part, the foci are definition, terminology, and diagnosis.

\section{Articles}

A PubMed search was performed in December 2014 with the terms "carotid near-occlusion," "carotid pseudo-occlusion," "carotid string sign," "carotid slim sign," "carotid critical stenosis," "small distal carotid artery," "narrow distal carotid artery," "carotid preocclusive stenosis," "carotid pre occlusive stenosis," "carotid subtotal stenosis," "carotid sub total stenosis," "carotid subtotal occlusion," "carotid sub total occlusion," "carotid functional occlusion," "carotid sub-occlusion," "carotid hypoplasia," "carotid incomplete occlusion," and "carotid hairline," without search restrictions. This yielded 1076 articles. Title review selected 115 articles of greatest interest. Excluded were articles not in English $(n=14)$ and those with inaccessible abstracts or full articles $(n=4)$. Excluded were 26 articles with $\leq 5$ cases $(n=8)$, not carotid near-occlusion $(n=16)$, in a non-peerreviewed journal $(n=1)$, and not analyzing humans $(n=1)$. Seventy-one articles were audited. All reference lists were examined, rendering an additional 17 articles. Two key articles ${ }^{1,22}$ were deemed likely to be cited; we examined all articles that had cited these articles by using the Web of Science data base, yielding 3 additional articles. In total, 91 articles were reviewed. 


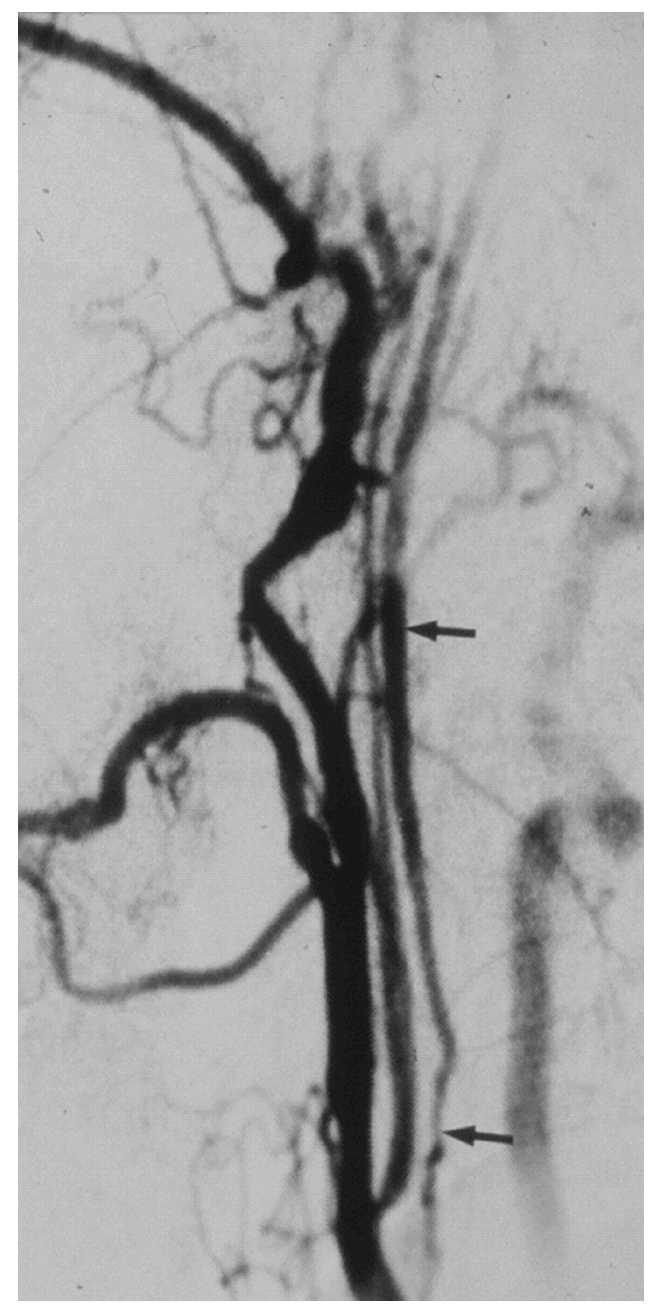

FIG 1. A case with near-occlusion with full collapse, reprinted with permission from Fox et al.' Lateral common carotid angiogram shows the thin, threadlike, collapsed lumen (arrows) of the ICA above a prominent ICA stenosis at the bulb (not shown).

\section{Definition of Near-Occlusion}

A carotid near-occlusion is a very tight atherosclerotic stenosis in which the artery beyond the stenosis is collapsed. ${ }^{1}$ The remaining patency differs from that in total occlusions and is separate from that in conventional carotid stenoses because of this collapse. ${ }^{1}$ Near-occlusion can be with and without full collapse: Near-occlusion with full collapse shows pronounced distal collapse with a threadlike lumen. ${ }^{1,21}$ Near-occlusion without full collapse shows a less pronounced distal collapse with a more normal-appearing distal artery. ${ }^{1,21}$

Previous Definition of Near-Occlusion. To the best of our knowledge, near-occlusion and its synonym terms are limited in publications to "near-occlusion with full collapse" between 1970 and 1997, with only 1 exception (presented below). ${ }^{1,2}$ Before 1997, partial near-occlusion was largely unrecognized, and such cases were likely considered usual stenoses. In 1997, NASCET collaborators redefined near-occlusion, including less complete collapse, more subtle than that previously known, ${ }^{2}$ effectively presuming that ICAs beyond severe stenosis would progressively decrease from their normal caliber to fully collapsed as a critical degree is reached rather than experiencing sudden collapse. Near-occlu-

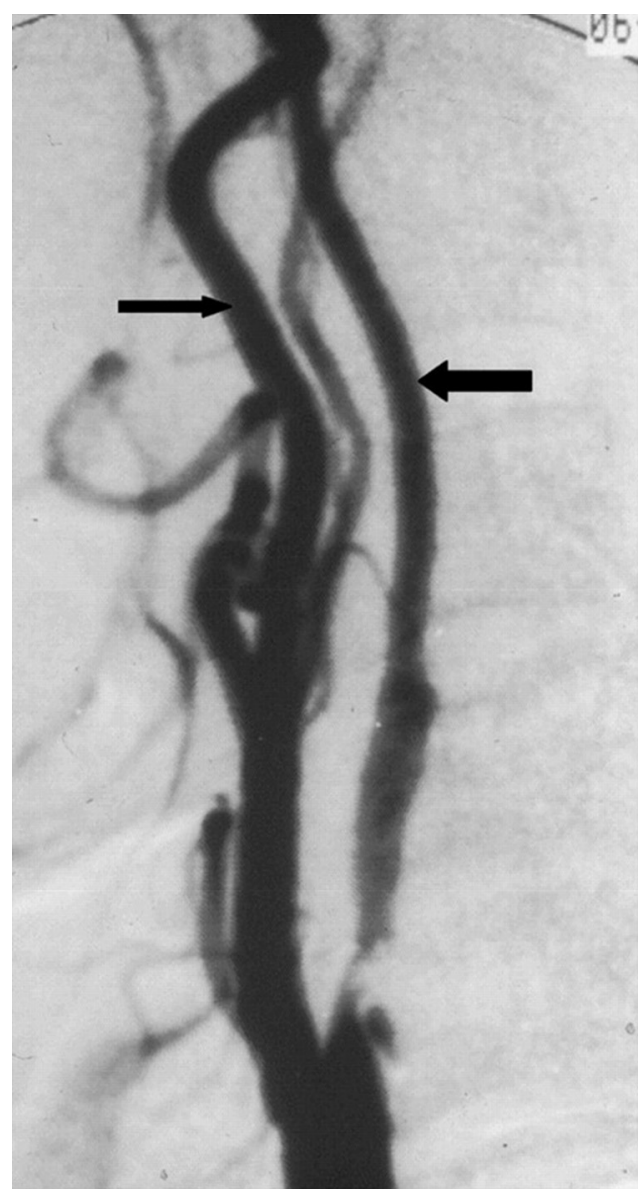

FIG 2. A case with near-occlusion without full collapse, reprinted with permission from Fox et al.' Lateral carotid angiogram shows a reduced ICA lumen distal to the stenosis (larger arrow); the diameter is slightly less than the ECA diameter (smaller arrow). The distal ICA lumen is normal-appearing (not threadlike).

sions were then subdivided into those with or without pronounced collapse, also called near-occlusion with and without the "string sign" (here called "near-occlusion with and without full collapse"). ${ }^{2}$

\section{Terminology}

First Descriptions Found in our Article Search. A collapsed ICA on cervical angiography was described by Riishede and Ethelberg $^{78}$ in 1953, caused by raised intracranial pressure in brain death. A case of possible near-occlusion was described as "teilweisem verschluss" (roughly "partial closure") in German by Mumenthaler et $\mathrm{al}^{79}$ in 1961, though without special attention to distal collapse compared with conventional stenosis or occlusion. Lippman et $\mathrm{al}^{75}$ clearly described distal collapse from atherosclerosis in 1970

Slim Sign. Lippman et $\mathrm{al}^{75}$ also called distal collapse the "poststenotic carotid slim sign" (later simply "slim sign") and "spurious hypoplasia" (false hypoplasia). ${ }^{75}$ Several subsequent authors inappropriately dropped "spurious" when referencing this article ("hypoplasia" instead of "false hypoplasia"). ${ }^{1,12,18,45}$ Radiographs published by Lippman et al today fit near-occlusion with full collapse. However, the "slim sign" has not been used 
as the main term in any near-occlusion article after that of Lippman et al; it has been used as a synonym of the main term. ${ }^{1,2,4,6,9-20,28,31,45,47-51,55,59,60,62,64,68,69,71,72}$

Pseudo-Occlusion. The term "pseudo-occlusion" was used for cases with raised intracranial pressure by Newton and Couch in $1960 .^{80}$ In 1978, Macpherson ${ }^{54}$ suggested pseudo-occlusions as possibly caused by "thrombosis or embolus." In 1980, Sekhar et $\mathrm{al}^{51}$ suggested "atheromatous pseudo-occlusion" to separate atherosclerotic causes from similar findings caused by raised intracranial pressure, intracranial occlusion, dissection, and hypoplasia. Images from Sekhar et al can be called "near-occlusion with full collapse." "Pseudo-occlusion" has been used for the appearance of a collapsed artery, ${ }^{1-9,11,13-20,45-48,56-62,65-70}$

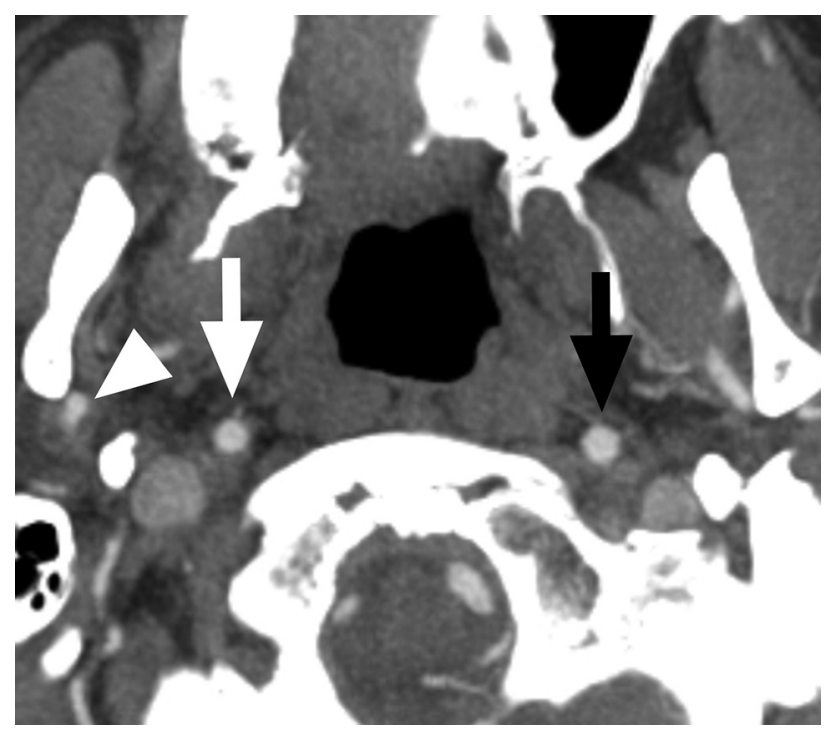

FIG 3. A case with a conventional carotid stenosis and no distal collapse. Axial CTA at the level of the distal extracranial ICA. The distal ICA (white arrow) is similar to, though slightly smaller than, the contralateral ICA (black arrow) and is wider than the right ECA (arrowhead).

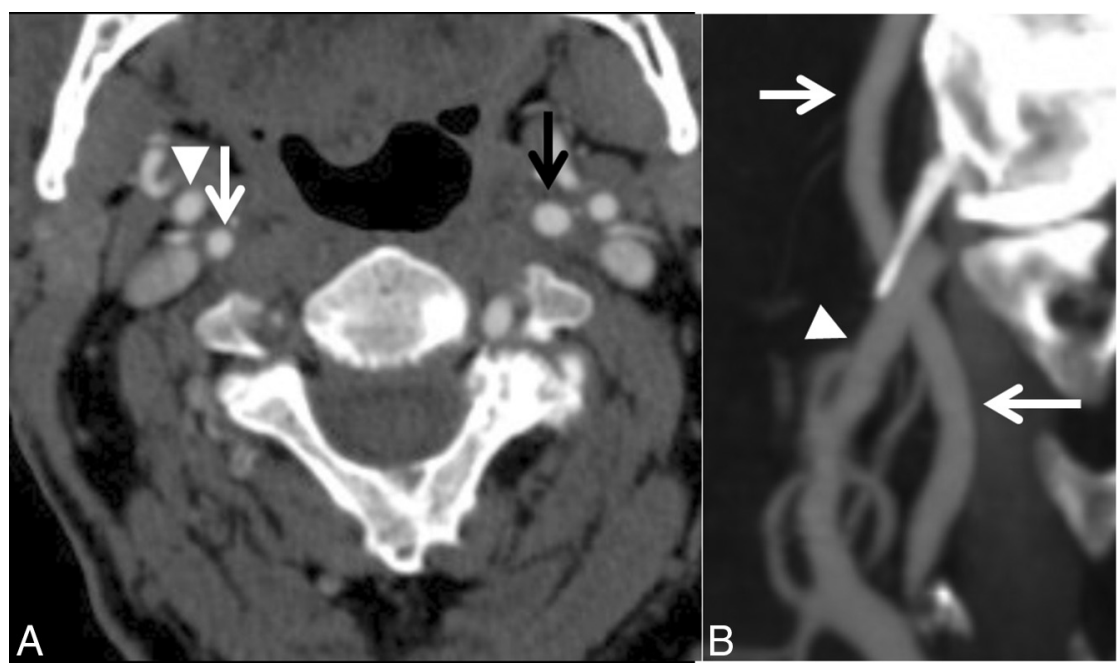

FIG 4. A case with near-occlusion without full collapse. A, Axial CTA at the level of the distal extracranial ICA. B, Sagittal reformat of $A$. The distal right ICA (white arrow) is narrower than the contralateral ICA (black arrow) and similar to the right ECA (arrowhead) but otherwise is normalappearing (not threadlike). but also quite literally when diagnosis changed from occlusion to patent after re-review (not necessarily with distal collapse. ${ }^{10,12,55,63,64,81}$

String Sign. The "string sign" was first used for distal ICA collapse in spontaneous dissection as coined by Ojemann et al in $1972 .{ }^{82} \mathrm{In}$ 1980, Mehigan and Olcott ${ }^{71}$ used the "string sign" term to describe the appearance of a distal artery collapse and presented several cases with different causes: dissection, postradiation carotid disease, and various forms of atherosclerosis or thrombosis. Since then, "string sign" has often described near-occlusion with full collapse (excluding nonatherosclerotic causes). Those who recognized near-occlusion as with and without full collapse have often used with and without the "string sign" to describe this. ${ }^{2,7,22,24,26}$

Near-Occlusion. "Nearly occluded" was used by Gabrielsen et $\mathrm{al}^{31}$ in 1981 to describe a tight carotid stenoses with distal collapse. They noted that the reduced caliber usually (not always) was severe, though they featured a case of near-occlusion without full collapse; this is the first instance we found in our article search. However, Gabrielsen et al did not suggest that "near-occlusion" should mean something other than "slim sign."

Narrowing of the Internal Carotid Artery (ICA/Common Carotid Artery Ratio). Not recognizing narrowing of the distal artery as near-occlusion was not considered problematic for the European Carotid Surgery Trial because it calculated stenosis degree by measuring the diameter at maximal stenosis compared with the unseen original ICA bulb diameter (European Carotid Surgery Trial grading system). ${ }^{36}$ As a secondary analysis, the authors identified patients with a collapsed distal artery by examining a ratio between the distal ICA and common carotid artery (ICA/common carotid artery ratio $)^{42}$ (different from their grading of stenosis by using the common carotid artery method ${ }^{83}$ ). The collaborators examined neck sides with $<50 \%$ European Carotid Surgery Trial-type stenosis (similar to $<30 \%$ NASCET-type stenosis ${ }^{83}$ ) and derived a threshold of $<0.42$ for ICA narrowing (mean \pm 2 SDs $)^{42}$

Recommendation. Regardless of which term one chooses, it is important to recognize that near-occlusions with and without full collapse exist. We recommend the term "near-occlusion" because it was used in large clinical trials to describe atherosclerotic stenosis with a distal collapse. ${ }^{1,2,32}$ We suggest not using "pseudo-occlusion" or "string sign" because of their use for other entities. "Slim sign" was used to describe nearocclusions with full collapse, but not for near-occlusion without full collapse; the use of "slim sign" might cause confusion. Therefore, when we discussed the terminology to use in a recent article, ${ }^{21}$ near-occlusion with and without full collapse was introduced and we recommended it for consistent use henceforth. 


\section{Diagnosis}

Near-occlusion with full collapse above a prominent ICA bulb stenosis is easy enough to recognize. However, occlusion can be misdiagnosed with suboptimal imaging and interpretation (Table 1). An ICA occlusion definition requires identification of the ascending pharyngeal artery as a tiny artery ascending adjacent to the expected course of the unseen ICA, but with typical branches just below the skull base. Collapsed near-occlusion smoothly continues into the carotid canal of the temporal bone; the ascending pharyngeal artery is a second nearby vessel. True ICA hypoplasia or long distal ICA tapering of dissection does not show a prominent ICA bulb stenosis. Quality interpretation separates atherosclerosis from high intracranial pressure and postradiation carotid disease. It is also important to consider distal stenoses/ occlusions by assessing the main cervical and intracranial arteries for the rare ICA hypoplasia, which shows a tiny bony carotid canal.

Near-occlusion without full collapse can be mistaken for conventional stenosis if one does not constantly search for subtle

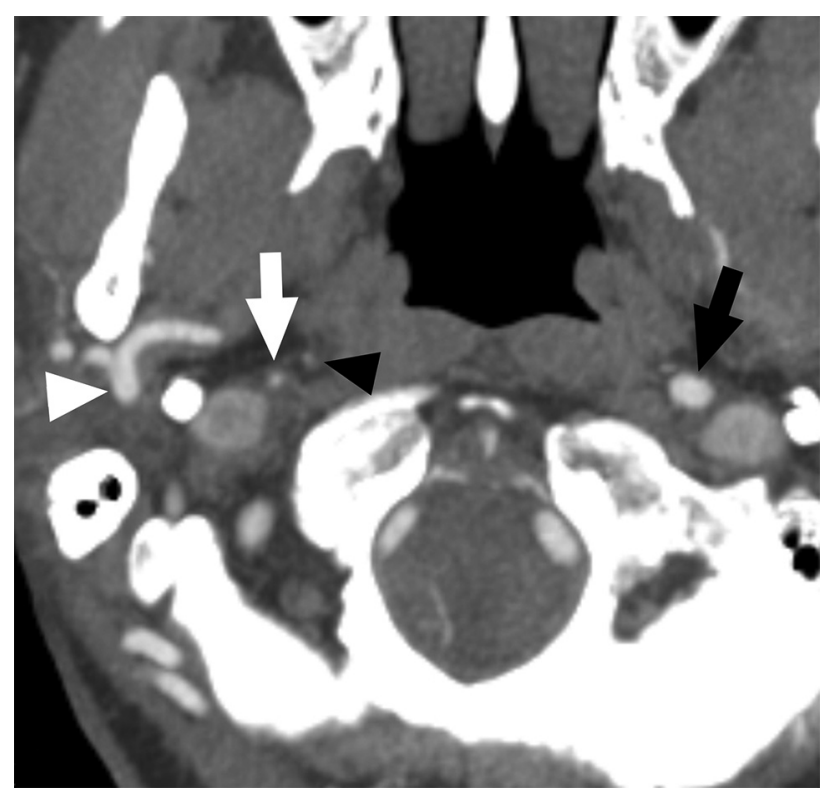

FIG 5. A case with near-occlusion with full collapse. Axial CTA at the level of the distal extracranial ICA. The distal right ICA (white arrow) is clearly collapsed with a threadlike appearance, clearly narrower than the contralateral ICA (black arrow) and the right ECA (white arrowhead). The black arrowhead points to the left ascending pharyngeal artery, ensuring that this is not an ICA occlusion. distal collapse. The NASCET collaborators recognized that if a collapsed distal ICA is used for percentage caluculation, the stenosis will be underrated. The NASCET method uses the normal distal ICA for percentage ${ }^{1,84}$ and requires near-occlusion assessment first. If you do not seek it, you will not find it.

One should also not overcall near-occlusion without full collapse. The relative small size of a distal ICA with a larger contralateral ICA can be an anatomic variation. Other causes of asymmetry exist: intracranial occlusion/stenosis and variance of ICA size depending on circle of Willis variations, such as a fetal posterior cerebral artery or a single ICA supplying both anterior cerebral arteries. Artery diameter can fluctuate slightly: It is important to apply the best diagnostic judgment for reasons of variance. In case of contralateral disease, emphasis should shift toward the comparison of the distal ICA and ipsilateral external carotid artery (ECA). ${ }^{22}$ Consistent diagnostic judgment is needed regarding true distal collapse as reduced: Diagnostic criteria presented below are aids for that. NASCET suggested early on not to calculate percentage stenosis if near-occlusion could be interpreted, ${ }^{84}$ yet it seems that not all who assess percentage stenosis look for subtle near-occlusion. ${ }^{34}$

Sometimes a nearly occluded stenosis is associated with intraluminal thrombus, ${ }^{85}$ a near-occlusion variant. Because the prognosis likely differs, it is reasonable that the presence of a thrombus be mentioned specifically in both clinical and scientific articles.

Most articles on near-occlusion were based on conventional angiography, so we present diagnostic issues based on that technique, with some added aspects of other modalities. Diagnostic studies of near-occlusion need interpretation with caution because there can be misdiagnoses of near-occlusion as occlusion due inadequate angiography findings if a long-enough delay was not allowed, further adding skepticism to occlusion diagnosed with screening tests. The use of conventional angiography is no guarantee of a criterion standard study.

Separating Near-Occlusion from Occlusion. Some suggested "occlusions" are indeed patent, needing angiography time to detect delayed contrast through a severely collapsed artery. ${ }^{23}$ Contrast remaining through the venous phase has been reported. ${ }^{23}$ The ascending pharyngeal artery should be seen as a tiny artery separate from and running parallel to an occluded or nearly occluded ICA. The ascending pharyngeal artery can be overlooked

Table 1: Mimics of near-occlusion on conventional angiography and CTA

\begin{tabular}{lll}
\hline \multicolumn{1}{c}{ Cause } & \multicolumn{1}{c}{ Mimic } & Way to Separate/Reason for Mimic \\
\hline $\begin{array}{l}\text { Similar appearance, but not } \\
\text { atherosclerosis }\end{array}$ & Dissection & $\begin{array}{c}\text { Cervical ICA lesion without severe bulb stenosis, possibly } \\
\text { patient history } \\
\text { Patient history, likely no focal stenosis }\end{array}$ \\
& High ICP & Patient history, possibly no focal stenosis \\
& Postradiation disease & No prominent bulb stenosis, narrow bony canal \\
Hypoplasia & Delayed images reveal patent lumen \\
Interpretation & NrOc mistaken for occlusion & Ascending pharyngeal artery mistaken for ICA \\
& Occlusion mistaken for NrOc & Larger opposite ICA from anatomic variations: \\
& Stenosis mistaken for NrOc & opposite ICA supplies fetal PCA and/or both ACAs \\
& NrOc mistaken for stenosis & Partially collapsed NrOc overlooked as a \\
& normal lumen when it is not threadlike \\
& Intracranial disease mistaken for NrOc & Exclude distal disease as cause for the collapse
\end{tabular}

Note:-PCA indicates posterior cerebral artery; ICP, intracranial pressure; NrOc, near-occlusion; ACA, anterior cerebral artery. 

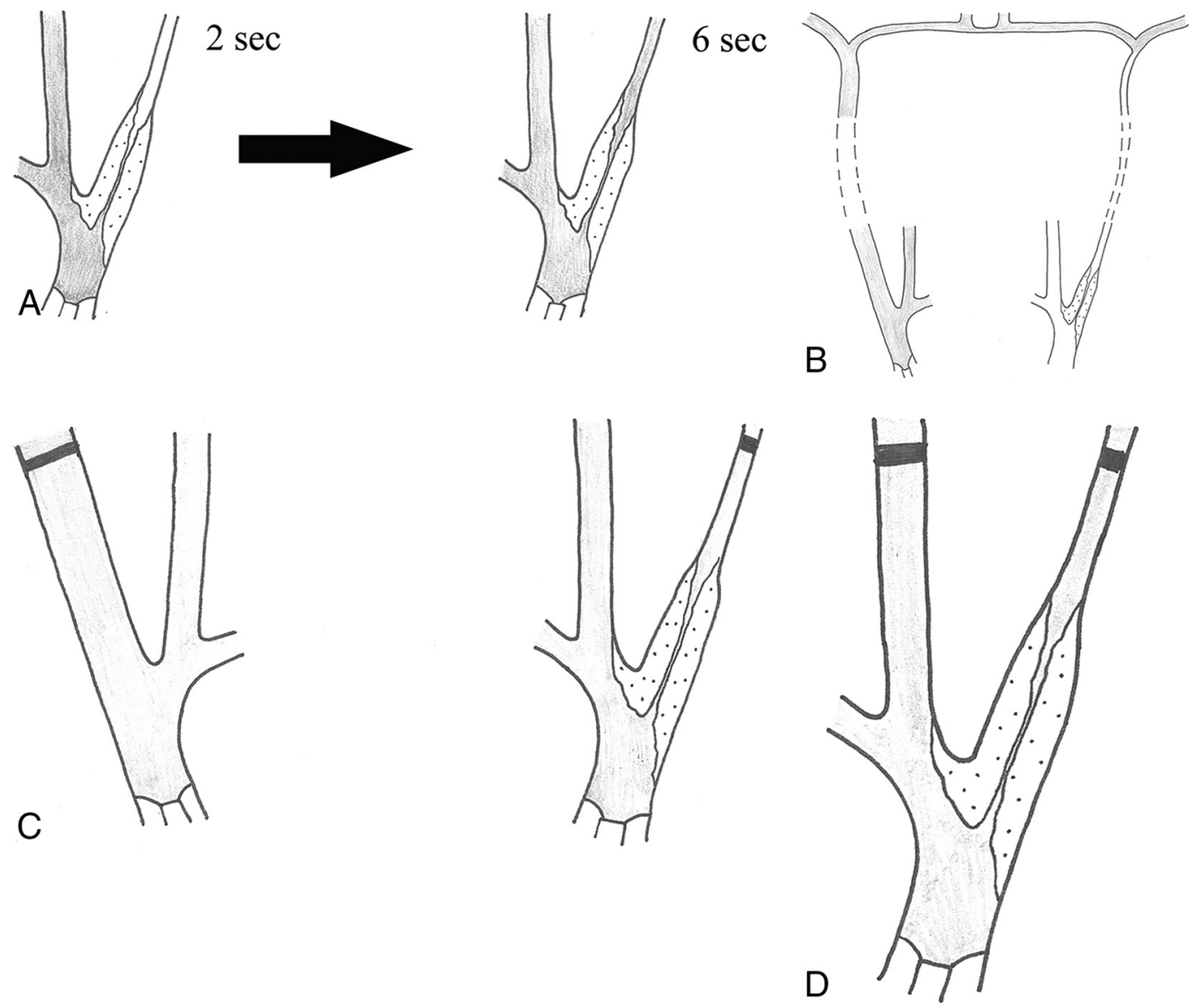

FIG 6. Schematic drawing of the 4 criteria for near-occlusion on conventional angiography. Delayed filling (A), evidence of intracranial collaterals when the contralateral side is examined (B), ipsilateral distal ICA less than the contralateral distal ICA (C), and ipsilateral distal ICA equal to or less than the ipsilateral ECA $(D)$. In all figures, the contrast is gray.

as a collapsed ICA in cases of ICA occlusion ("pseudostring $\left.\operatorname{sign}^{11}\right)$.

Separating Near-Occlusion from Conventional Stenosis. NASCET used descriptive criteria to distinguish near-occlusion (with and without full collapse) from conventional stenosis: 1) delayed filling, 2) intracranial collaterals, 3) ipsilateral distal ICA less than the contralateral distal ICA, and 4) ipsilateral distal ICA equal to or less than the ipsilateral ECA (the ICA normally is substantially larger than the ECA) (Fig 6). Two of the 4 criteria were required for diagnosis. ${ }^{1}$ Separating near-occlusion is justifiable from its observed lower stroke risk compared with severe stenosis, and the potential fallacious calculation of percentage stenosis if not recognized, yielding incorrect percentages as low as 50\%-60\%, potentially managed differently. ${ }^{1}$

Separating Near-Occlusion with Full Collapse from Near-Occlusion without Full Collapse. Near-occlusion can be fully collapsed or without full collapse. The current diagnostic criterion for nearocclusion with full collapse is a "threadlike" distal lumen (with variations). ${ }^{1}$ The transition between near-occlusion with and without full collapse is not distinct. Even so, $90 \%$ agreement was reported in a small study $(n=21)$ between blinded reviewers separating near-occlusions with and without full collapse by using descriptive criteria alone. ${ }^{21}$ Fully collapsed near-occlusion shows striking ICA collapse and can be overlooked as complete occlu- sion if images or interpretation are suboptimal. All cases of presumed occlusion need delayed study to seek a late, slow-flowing collapsed lumen. With CTA, ICA occlusion diagnosis may be incorrect without a delayed CTA phase or a routine postcontrast head CT for possible ICA filling-in at the skull base or carotid canal to identify near-occlusion. The incidence of delayed studies with CTA changing the diagnosis from occlusion to near-occlusion is not well-known; certainly near-occlusions with full collapse are seen with CTA, even without delayed studies. ${ }^{70}$

Diagnosis with Sonography. There are several mimics of nearocclusion for sonography (Table 2). Sonography aspires to distinguish near-occlusion and occlusion by the presence or absence of flow. Accuracy depends on the sonographic methodology with more accurate distinctions by using Color Doppler with pulsed wave velocity measurements and Power Doppler than the outdated continuous wave technique. ${ }^{8,17,23,45,67,69}$ Color Doppler with pulsed wave velocity measurements has been reported as separating near-occlusion from occlusion with good accuracy. ${ }^{8,17,23,45,67}$ Presumably, the small error rate includes very slow and collapsed near-occlusion cases with nondetectable flow. Perhaps the commonly used additional method, power Doppler, may better detect slow flow, but only 2 small studies analyzed this. ${ }^{5,17}$ Adding transoral sonography to also assess distal artery patency at the level of the pharynx 
Table 2: Ultrasound-specific mimics of near-occlusion

\begin{tabular}{lll}
\hline \multicolumn{1}{c}{ Cause } & \multicolumn{1}{c}{ Mimic } & \multicolumn{1}{c}{ Reason for Mimic } \\
\hline Imaging protocol & NrOc mistaken for occlusion & Small low-flow channel not visualized \\
Interpretation & NrOc mistaken for intracranial disease & Low flow with systolic spikes could be either \\
& NrOc mistaken for no stenosis & Normal velocities with tight stenosis on B-mode \\
Limitation of ultrasound & NrOc mistaken for stenosis & NrOc without full collapse has high flow velocities \\
\hline
\end{tabular}

Note:-NrOc indicates near-occlusion.

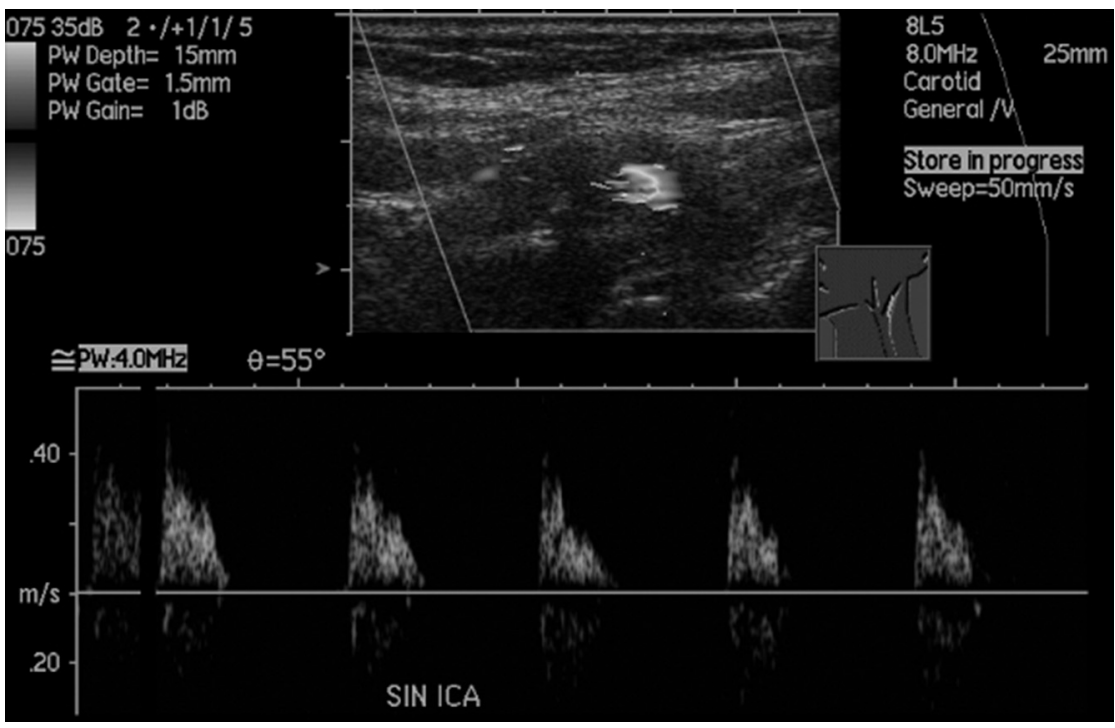

FIG 7. Sonographic findings of near-occlusion with full collapse. It is difficult to discern the narrow flow channel despite the low-flow setting and very low-flow velocities with systolic spikes without diastolic flow. CTA confirmed the diagnosis with a patent fully collapsed distal ICA (not shown).

shows promising initial findings. ${ }^{8}$ Contrast-enhanced sonography might also increase the accuracy, but this has not been evaluated.

Near-occlusion with full collapse can be seen on sonography with very low flow velocity. The typical recognized sonography appearance is a very tight stenosis with a minimal flow channel, slow flow velocities, and a grossly pathologic flow profile (Fig 7). This finding is $71 \%(42 / 59)$ sensitive ${ }^{5,45,67}$ and $98.8 \%(932 / 943)$ specific $^{45,67}$ for near-occlusion with full collapse. Dampened, pseudovenous flow with low pulsatility is highly specific as published in Mansour et $\mathrm{al},{ }^{45}$ with only 1 false-positive with distal occlusion. A flow profile with systolic triangular spikes and no diastolic flow can be either distal occlusion or stenosis ${ }^{5,18,45,47}$ or near-occlusion with full collapse ${ }^{12,18,67,76}$; the sonography report should reflect this uncertainty. Systolic spikes with reversed diastolic flow have been reported in a small series. ${ }^{8}$ False-negatives were either mistaken occlusions or mistaken conventional stenosis with high flow velocity. Rarely, an important pitfall is when velocity drops to the range of normal flow; a peak systolic velocity of $140 \mathrm{~cm} / \mathrm{s}$ was presented by Bowman et al. ${ }^{18}$ As such, the appearance with 2D B-mode of a very tight stenosis and "normal" flow velocities does not add up, requiring suspicion of near-occlusion. However, if the stenosis appearance on B-mode is ignored, the near-occlusion can be mistakenly reported as "no significant stenosis."

Near-occlusions without full collapse seems indistinguishable from conventional stenosis because both have high flow velocities. $^{5,21}$ However, near-occlusion without full collapse has only been analyzed for peak systolic velocity in 2 studies totalling 30 patients, ${ }^{5,21}$ and one of these studies did not clearly define near-occlusion without full collapse. ${ }^{5}$ Thus, more than peak systolic velocity is needed to distinguish nearocclusion without full collapse from conventional stenoses.

Thus, when very tight stenosis with low flow is detected, it is often nearocclusion with full collapse, though possibly distal disease. Angiographic confirmation (with CTA including delayed images) is reasonable. A finding of a suggested $>70 \%$ carotid stenosis with velocity on sonography can be $>70 \%$ stenosis or a near-occlusion. Thus, virtually all near-occlusions without full collapse and some nearocclusions with full collapse can be overlooked if sonography is used alone.

Diagnosis with CTA. CTA diagnostic accuracy to separate nearocclusion from occlusion has been moderately studied. In 2 studies, 30/30 near-occlusions and 33/33 occlusions were correctly identified. ${ }^{33,37}$ Separating near-occlusions (mostly partial near-occlusion) from conventional stenosis has been less analyzed. In 1 study, 4/4 near-occlusion (at least 1 was without full collapse) and 22/22 30\%-99\% stenoses were correctly distinguished. ${ }^{33}$ Further studies that include delayed imaging are needed.

With a consistent expert observer as the criterion standard, Bartlett et $\mathrm{al}^{22}$ presented CTA-specific diameter-measurement criteria for separating near-occlusion (with and without full collapse) from conventional stenoses: 1) stenosis diameter of $\leq 1.3$ $\mathrm{mm}, 2$ ) ipsilateral distal ICA diameter of $\leq 3.5 \mathrm{~mm}, 3$ ) ipsilateral distal ICA/contralateral distal ICA ratio of $\leq 0.87$, and 4 ) ipsilateral distal ICA/ipsilateral ECA of $\leq 1.27$. These criteria were not compared with those of conventional angiography.

MRA Diagnosis. MRA literature for near-occlusion is limited. To diagnose near-occlusion versus occlusion, TOF MRA is limited because slow-flow signal likely is below the visibility threshold; $2 \mathrm{D}$ TOF may be superior to 3D TOF. ${ }^{5,17}$ Approximately 75\% (14/19) of all near-occlusions show a flow gap on $2 \mathrm{D}$ TOF. ${ }^{5}$ A flow gap seems similarly common for near-occlusion both with full collapse and without full collapse, though that study did not clearly separate the near-occlusion types. ${ }^{5}$ Segmental flow gaps suggest vessel patency because occlusions are more likely to show fulllength signal absence. ${ }^{5}$ While it was suggested that the clinical 
usefulness of TOF MRA is limited because distal occlusions can present with flow gaps, ${ }^{5}$ it is uncertain that these were truly distal occlusions. No study sought to separate near-occlusions from conventional stenosis. Contrast-enhanced MRA for near-occlusion is scarcely studied. ${ }^{5}$

Alternative Diagnostic Criteria. After publication of the 2005 NASCET/European Carotid Surgery Trial near-occlusion criteria with conventional angiography in $2005,{ }^{1}$ modifications were suggested. A numeric ipsilateral distal ICA/contralateral distal ICA ratio of $<0.5$ was sought from one report, ${ }^{28}$ and $<0.2,{ }^{35}$ from another. With CTA criteria for near-occlusion, a side-to-side ratio of only $\leq 0.87$ suggested near-occlusion (with and without full collapse), though the authors concluded that an overall interpretation be used rather than measurements because of the variability of disease and anatomic variants to diagnose partial near-occlusion. ${ }^{22}$ However, the $\leq 0.87$ ratio was derived from diagnostic analyses, ${ }^{22}$ whereas the other 2 ratios were presented without reference to how they were derived. ${ }^{28,35}$ It seems that these measured criteria transfer the diagnosis of near-occlusion from a skilled interpretation to synthesized numbers applied without the same skill.

The minimal diameter of maximal stenosis on CTA is an alternative way to grade stenoses, replacing percentage calculations to avoid measuring the distal artery. ${ }^{86}$ This would remove inconsistencies and ambiguities of creating percentage stenosis. If that method is used, the presence or absence of near-occlusions may still need to be assessed to list near-occlusions separately.

\section{Recommendation}

CTA is suggested for current near-occlusion diagnosis. CTA is very accurate in separating near-occlusion from occlusion with delayed imaging, and criteria exist to separate near-occlusion (with and without full collapse) from conventional stenoses. The usual technical concerns with CTA, contrast and radiation, apply. In comparison with conventional angiography, the criteria can be more specific with absolute measurements, with no procedural stroke risk.

The diagnosis of complete ICA occlusion needs delayed imaging to exclude the slowly filling distal ICA of near-occlusion with full collapse. That can be a routine postcontrast head CT after CTA (which also evaluates enhancing brain lesions and delayed collateral pial arteries not shown on initial "snapshot" CTA) or multiphased CTA. While enhanced MRA could show some slow distal ICAs, with acquisition longer than that in the subsecond scan of CTA at each level, MRA, however, has inherent lower spatial resolution.

For sonography, emphasis has often been on the separation of near-occlusion and occlusion; possibly this can be further improved with power Doppler and/or contrast enhancement. More important, it is impossible to separate near-occlusion without full collapse from conventional stenoses with sonography. This lack of sensitivity is a relatively recent finding (from 2014 ${ }^{21}$ ), and many recommendations for diagnostic work-up predated this finding. Recommendations for the diagnostic work-up should be revised accordingly. It seems appropriate to always perform CTA in addition because near-occlusions can be missed with sonogra- phy, and those that are detected might be caused by distal occlusion or stenosis.

MRA with 2D TOF or contrast enhancement can separate some near-occlusions from occlusion, but not all. It is uncertain whether MRA can consistently separate near-occlusion from conventional stenosis.

\section{Confusion and Need for Further Improvement}

Please refer to Part 2 of this review for the confusion and need for further improvement regarding the definition, terminology, and diagnosis of near-occlusion.

Disclosures: Elias Johansson—RELATED: Grant: several non-profit organizations,* Comments: standard research grants, listed in the footnotes; none had any influence over the work; conforms to "no disclosures." Allan J. Fox-UNRELATED: Expert Testimony: medical malpractice cases, none related to the topic of this article. *Money paid to the institution.

\section{REFERENCES}

1. Fox AJ, Eliasziw M, Rothwell PM, et al. Identification, prognosis, and management of patients with carotid artery near occlusion. AJNR Am J Neuroradiol 2005;26:2086-94 Medline

2. Morgenstern LB, Fox AJ, Sharpe BL, et al. The risks and benefits of carotid endarterectomy in patients with near occlusion of the carotid artery: North American Symptomatic Carotid Endarterectomy Trial (NASCET) Group. Neurology 1997;48:911-15 CrossRef Medline

3. Son S, Choi DS, Kim SK, et al. Carotid artery stenting in patients with near occlusion: a single-center experience and comparison with recent studies. Clin Neurol Neurosurg 2013;115:1976-81 CrossRef Medline

4. Sakamoto S, Kiura Y, Kajihara Y, et al. Carotid artery stenting using the proximal or dual protection method for near occlusion of the cervical internal carotid artery. Neurosurg Rev 2013;36:551-57; discussion 557-48 CrossRef Medline

5. El-Saden SM, Grant EG, Hathout GM, et al. Imaging of the internal carotid artery: the dilemma of total versus near total occlusion. $R a$ diology 2001;221:301-08 CrossRef Medline

6. Martin MA, Marotta TR. Vasa vasorum: another cause of the carotid string sign. AJNR Am J Neuroradiol 1999;20:259-62 Medline

7. Gil-Peralta A, González A, González-Marcos JR, et al. Internal carotid artery stenting in patients with symptomatic atheromatous pseudo-occlusion. Cerebrovasc Dis 2004; 17(suppl 1):105-12 CrossRef Medline

8. Fujimoto S, Toyoda K, Kishikawa K, et al. Accuracy of conventional plus transoral carotid ultrasonography in distinguishing pseudoocclusion from total occlusion of the internal carotid artery. Cerebrovasc Dis 2006;22:170-76 CrossRef Medline

9. Ogata T, Yasaka M, Kanazawa Y, et al. Outcomes associated with carotid pseudo-occlusion. Cerebrovasc Dis 2011;31:494-98 CrossRef Medline

10. Kniemeyer HW, Aulich A, Schlachetzki F, et al. Pseudo- and segmental occlusion of the internal carotid artery: a new classification, surgical treatment and results. Eur J Vasc Endovasc Surg 1996;12:310-20 CrossRef Medline

11. Archie JP. Carotid endarterectomy when the distal internal carotid artery is small or poorly visualized. J Vasc Surg 1994;19:23-30; discussion 30-31 CrossRef Medline

12. Ascher E, Markevich N, Hingorani A, et al. Pseudo-occlusions of the internal carotid artery: a rationale for treatment on the basis of a modified carotid duplex scan protocol. J Vasc Surg 2002;35:340-45 CrossRef Medline

13. Nikas DN, Ghany MA, Stabile E, et al. Carotid artery stenting with proximal cerebral protection for patients with angiographic appearance of string sign. JACC Cardiovasc Interv 2010;3:298-304 CrossRef Medline 
14. Ringelstein EB, Berg-Dammer E, Zeumer H. The so-called atheromatous pseudoocclusion of internal carotid artery: a diagnostic and therapeutical challenge. Neuroradiology 1983;25:147-55 CrossRef Medline

15. Terada T, Tsuura M, Matsumoto H, et al. Endovascular treatment for pseudo-occlusion of the internal carotid artery. Neurosurgery 2006;59:301-09; discussion 301-09 CrossRef Medline

16. O'Leary DH, Mattle H, Potter JE. Atheromatous pseudo-occlusion of the internal carotid artery. Stroke 1989;20:1168-73 CrossRef Medline

17. Fürst G, Saleh A, Wenserski F, et al. Reliability and validity of noninvasive imaging of internal carotid artery pseudo-occlusion. Stroke 1999;30:1444-49 CrossRef Medline

18. Bowman JN, Olin JW, Teodorescu VJ, et al. Carotid artery pseudoocclusion: does end-diastolic velocity suggest need for treatment? Vasc Endovascular Surg 2009;43:374-78 CrossRef Medline

19. Dimakakos PB. Carotid internal pseudo-occlusion: what should we do? Vasc Surg 1999;33:123-24 CrossRef

20. Hirata $\mathrm{Y}$, Sakata $\mathrm{N}$, Inoue $\mathrm{T}$, et al. Histopathological features with angiographic correlates of internal carotid artery pseudoocclusion: impact of plaque compositions-clinical article. J Neurosurg 2011;115:350-58 CrossRef Medline

21. Johansson E, Öhman K, Wester P. Carotid near-occlusion with full collapse might cause a high risk of stroke. J Int Med 2015;277:615-23 CrossRef Medline

22. Bartlett ES, Walters TD, Symons SP, et al. Diagnosing carotid stenosis near-occlusion by using CT angiography. AJNR Am J Neuroradiol 2006;27:632-37 Medline

23. Lee DH, Gao FQ, Rankin RN, et al. Duplex and color Doppler flow sonography of occlusion and near occlusion of the carotid artery. AJNR Am J Neuroradiol 1996;17:1267-74 Medline

24. Gonzalez A, Gil-Peralta A, Mayol A, et al. Internal carotid artery stenting in patients with near occlusion: 30-day and long-term outcome. AJNR Am J Neuroradiol 2011;32:252-58 CrossRef Medline

25. Paciaroni M, Caso V, Cardaioli G, et al. Is ultrasound examination sufficient in the evaluation of patients with internal carotid artery severe stenosis or occlusion? Cerebrovasc Dis 2003;15:173-76 CrossRef Medline

26. Choi BS, Park JW, Shin JE, et al. Outcome evaluation of carotid stenting in high-risk patients with symptomatic carotid near occlusion. Interv Neuroradiol 2010;16:309-16 Medline

27. Saba L, Mallarini G. Comparison between quantification methods of carotid artery stenosis and computed tomographic angiography. J Comput Assist Tomogr 2010;34:421-30 CrossRef Medline

28. Oka F, Ishihara H, Kato $S$, et al. Cerebral hemodynamic benefits after carotid artery stenting in patients with near occlusion. $J$ Vasc Surg 2013;58:1512-17 CrossRef Medline

29. Ruiz-Salmerón RJ, Gamero MA, Carrascosa C, et al. Carotid artery stenting: clinical and procedural implications for near-occlusion stenosis [Article in English, Spanish]. Neurologia 2013;28:535-42 CrossRef Medline

30. Edgell RC, Yavagal DR, Agner C, et al. Recanalization of a symptomatic extracranial internal carotid artery near occlusion with proximal and distal protection: technical case report. Neurosurgery 2007; 61:E174 CrossRef Medline

31. Gabrielsen TO, Seeger JF, Knake JE, et al. The nearly occluded internal carotid artery: a diagnostic trap. Radiology 1981;138:611-18 CrossRef Medline

32. Fox AJ. How to measure carotid stenosis. Radiology 1993;186: 316-18 CrossRef Medline

33. Leclerc X, Godefroy $\mathrm{O}$, Lucas $\mathrm{C}$, et al. Internal carotid arterial stenosis: CT angiography with volume rendering. Radiology 1999; 210:673-82 CrossRef Medline

34. Fox AJ, Symons SP, Aviv RI, et al. Falsely claiming use of NASCET percentage stenosis method. Radiology 2009;253:574-75; author reply 575 CrossRef Medline

35. Anzidei M, Napoli A, Marincola BC, et al. Gadofosveset-enhanced MR angiography of carotid arteries: does steady-state imaging im- prove accuracy of first-pass imaging? Comparison with selective digital subtraction angiography. Radiology 2009;251:457-66 CrossRef Medline

36. Rothwell PM, Gutnikov SA, Warlow CP. Reanalysis of the final results of the European Carotid Surgery Trial. Stroke 2003;34:514-23 CrossRef Medline

37. Chen C, Lee TH, Hsu HL, et al. Multi-slice CT angiography in diagnosing total versus near occlusions of the internal carotid artery: comparison with catheter angiography. Stroke 2004;35:83-85 Medline

38. Fox AJ, Symons SP, Aviv RI, et al. Should modeling methodology suppress anatomic excellence? Stroke 2009;40:3411-12 CrossRef Medline

39. Dix JE, McNulty BJ, Kalimes DF. Frequency and significance of a small distal ICA in carotid stenosis. AJNR Am J Neuroradiol 1998;19: 1215-18 Medline

40. Yadav JS. Functional occlusions of the carotid artery (string signs): to treat or not to treat? JACC Cardiovasc Interv 2010;3:305-06 CrossRef Medline

41. Henderson R, Eliasziw M, Fox AJ, et al. Angiographically defined collateral circulation and risk of stroke in patients with severe carotid artery stenosis: North American Symptomatic Carotid Endarterectomy Trial (NASCET) Group. Stroke 2000;31:128-32 CrossRef Medline

42. Rothwell PM, Warlow CP; On behalf of the European Carotid Surgery Trialists' Collaborative Group. Low risk of ischemic stroke in patients with reduced internal carotid artery lumen diameter distal to severe symptomatic carotid stenosis: cerebral protection due to low poststenotic flow? Stroke 2000;31:622-30 CrossRef Medline

43. Lev MH, Romero JM, Goodman DN, et al. Total occlusion versus hairline residual lumen of the internal carotid arteries: accuracy of single section helical CT angiography. AJNR Am J Neuroradiol 2003; 24:1123-29 Medline

44. Koutsoumpelis A, Kouvelos G, Peroulis M, et al. Surgical and endovascular intervention on internal carotid artery near occlusion. Int Angiol 2015;34:172-81 Medline

45. Mansour MA, Mattos MA, Hood DB, et al. Detection of total occlusion, string sign, and preocclusive stenosis of the internal carotid artery by color-flow duplex scanning. Am J Surg 1995;170:154-58 CrossRef Medline

46. Radak DJ, Tanaskovic S, Ilijevski NS, et al. Eversion carotid endarterectomy versus best medical treatment in symptomatic patients with near total internal carotid occlusion: a prospective nonrandomized trial. Ann Vasc Surg 2010;24:185-89 CrossRef Medline

47. Samson RH, Showalter DP, Yunis JP, et al. Color flow scan diagnosis of the carotid string sign may prevent unnecessary surgery. Cardiovasc Surg 1999;7:236-41 CrossRef Medline

48. Spacek M1, Martinkovicova L, Zimolova P, et al. Mid-term outcomes of carotid artery stenting in patients with angiographic string sign. Catheter Cardiovasc Interv 2012;79:174-79 CrossRef Medline

49. Androulakis AE, Labropoulos N, Allan R, et al. The role of common carotid artery end-diastolic velocity in near total or total internal carotid artery occlusion. Eur J Vasc Endovasc Surg 1996;11:140-47 CrossRef Medline

50. Giannoukas AD, Labropoulos N, Smith FC, et al. Management of the near total internal carotid artery occlusion. Eur J Vasc Endovasc Surg 2005;29:250-55 CrossRef Medline

51. Sekhar LN, Heros RC, Lotz PR, et al. Atheromatous pseudo-occlusion of the internal carotid artery. J Neurosurg 1980;52:782-89 CrossRef Medline

52. Greiner C, Wassmann H, Palkovic S, et al. Revascularization procedures in internal carotid artery pseudo-occlusion. Acta Neurochir (Wien) 2004;146:237-43 CrossRef Medline

53. Momjian-Mayor I, Burkhard P, Murith N, et al. Diagnosis of and treatment for symptomatic carotid stenosis: an updated review. Acta Neurol Scand 2012;126:293-305 CrossRef Medline

54. Macpherson P. Pseudo-occlusion of the internal carotid artery. $\mathrm{Br} \mathrm{J}$ Radiol 1978;51:5-10 CrossRef Medline 
55. Regina G, Testini M, Fullone M, et al. Pseudo-occlusion of the internal carotid artery: report of 15 cases and review of the literature. Int Angiol 1997;16:147-50 Medline

56. Pulli R, Frosini P, Gatti M, et al. Internal carotid pseudo-occlusion: early and late results. J Cardiovasc Surg (Torino) 1997;38:15-20 Medline

57. Heros RC, Sekhar LN. Diagnostic and therapeutic alternatives in patients with symptomatic "carotid occlusion" referred for extracranial-intracranial bypass surgery. J Neurosurg 1981;54:790-96 CrossRef Medline

58. Berman SS, Bernhard VM, Erly WK, et al. Critical carotid artery stenosis: diagnosis, timing of surgery and outcome. J Vasc Surg 1994;20:499-508; discussion 508-10 CrossRef Medline

59. Yonas H, Meyer J. Extreme pseudo-occlusion of the internal carotid artery. Neurosurgery 1982;11:681-86 CrossRef Medline

60. Romero JM, Lev MH, Chan ST, et al. US of neurovascular occlusive disease: interpretive pearls and pitfalls. Radiographics 2002;22: 1165-76 CrossRef Medline

61. Remonda L, Heid O, Schroth G. Carotid artery stenosis, occlusion, and pseudo-occlusion: first-pass, gadolinium-enhanced, three-dimensional MR angiography_preliminary study. Radiology 1998; 209:95-102 CrossRef Medline

62. Berman SS, Devine JJ, Erodes LS, et al. Distinguishing carotid artery pseudo-occlusion with color-flow Doppler. Stroke 1995;26:434-38 CrossRef Medline

63. Sitzer M, Fürst G, Fischer H, et al. Between-method correlation in quantifying internal carotid stenosis. Stroke 1993;24:1513-18 CrossRef Medline

64. Ammar AD, Turrentine MW, Farha SJ. The importance of arteriographic interpretation in occlusion or pseudo-occlusion of the carotid artery. Surg Gyn Obst 1988;167:119-23 Medline

65. Barker CM, Gomez J, Grotta JC, et al. Feasibility of carotid artery stenting in patients with angiographic string sign. Catheter Cardiovasc Interv 2010;75:1104-09 CrossRef Medline

66. Bazan HA. Carotid string sign is not necessarily a functional occlusion: admit, anticoagulate, and revascularize urgently. Catheter Cardiovasc Interv 2010;75:1110 CrossRef Medline

67. Hetzel A, Eckenweber B, Trummer B, et al. Colour-coded duplex sonography of preocclusive carotid stenoses. Eur J Ultrasound 1998; 8:183-91 CrossRef Medline

68. Kashyap VS, Clair DG. Carotid string sign. J Vasc Surg 2006;43:401 CrossRef Medline

69. Fredericks RK,ThomasTD, Lefkowitz DS, et al. Implications of the angiographic string sign in carotid atherosclerosis. Stroke 1990;21: 476-79 CrossRef Medline

70. Bennett DL, Hamberg LM, Wang B, et al. Diagnostic yield of delayed phase imaging in CT angiography of the head and neck: a retrospective study. PLoS One 2014;9:e99020 CrossRef Medline

71. Mehigan JT, Olcott C 4th. The carotid "string" sign. Differential diagnosis and management. Am J Surg 1980;140:137-43 CrossRef Medline

72. Labropoulos N, Androulakis A, Allan R, et al. The value of colour flow imaging in the detection of subtotal and total internal carotid artery occlusion. Vasc Endovasc Surg 1997;31:7757-59 CrossRef

73. Gross K, Wang H. The string sign. J Vasc Nurs 2000;18:72 CrossRef Medline

74. Pappas JN. The angiographic string sign. Radiology 2002;222:237-38 CrossRef Medline

75. Lippman HH, Sundt TM Jr, Holman CB. The poststenotic carotid slim sign: spurious internal carotid hypolasia. Mayo Clin Proc 1970; 45:762-67 Medline

76. Görtler M, Niethammer R, Widder B. Differentiating subtotal carotid artery stenoses from occlusions by colour-coded duplex sonography. J Neurol 1994;241:301-05 CrossRef Medline

77. Szabo K, Kern R, Gass A, et al. Acute stroke patterns in patients with internal carotid artery disease: a diffusion-weighted magnetic resonance imaging study. Stroke 2001;32:1323-29 CrossRef Medline

78. Riishede J, Ethelberg S. Angiographic changes in sudden and severe herniation of the brain stem through the tentorial incisure: report of five cases. AMA Arch Neural Psychiatry 1953;70:399-409 CrossRef Medline

79. Mumenthaler VM, Wellauer J, Schamaun M. “Apoplexie” bei vollständigen und unvollständigen Carotisverschlüssen. Helv Med Acta 1961;28:705-40, continued 808-30

80. Newton TH, Couch RSC. Possible errors in the arteriographic diagnosis of internal carotid artery occlusion. Radiology 1960;75:766-73 CrossRef Medline

81. Marquering HA, Nederkoorn PJ, Beenen LF, et al. Carotid pseudoocclusion on CTA in patients with acute ischemic stroke: a concerning observation. Clin Neurol Neurosurg 2013;115:1591-94 CrossRef Medline

82. Ojemann RG, Fisher CM, Rich JC. Spontaneous dissecting aneurysm of the internal carotid artery. Stroke 1972;3:434-40 CrossRef Medline

83. Rothwell PM, Gibson RJ, Slattery J, et al. Equivalence of measurements of carotid stenosis: a comparison of three methods on 1001 angiograms-European Carotid Surgery Trialists' Collaborative Group. Stroke 1994;25:2435-39 CrossRef Medline

84. Bartlett ES, Walters TD, Symons SP, et al. Quantification of carotid stenosis on CT angiography. AJNR Am J Neuroradiol 2006;27:13-19 Medline

85. Buchan A, Gates P, Pelz D, et al. Intraluminal thrombus in the cerebral circulation: implications for surgical management. Stroke 1988;19:681-87 CrossRef Medline

86. North American Symptomatic Carotid Endarterectomy Trial (NASCET) Steering Committee. North American Symptomatic Carotid Endarterectomy Trial: methods, patient characteristics, and progress. Stroke 1991;22:711-20 CrossRef Medline 